\section{La arquitectura moderna}

\section{Modern architecture}
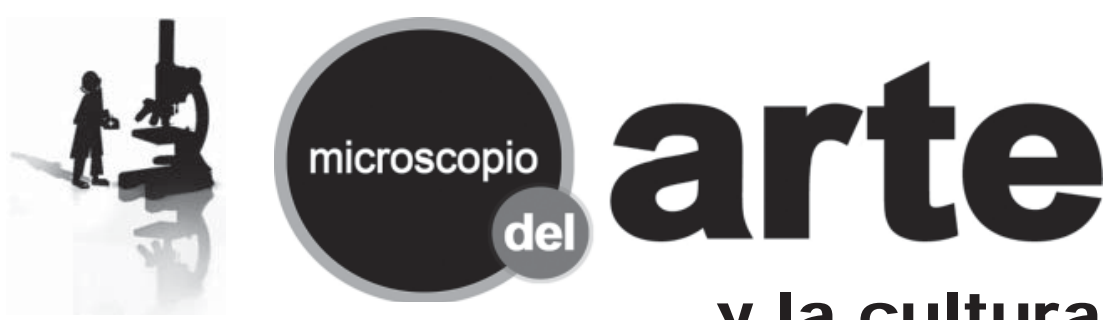

\section{y la cultura}

Es en el período de entre guerras donde se gesta, cristaliza y se desarrolla todo lo que actualmente conocemos como moderno en términos urbanísticos y arquitectónicos.

Cinco grandes nombres son los que brillan en el panorama de la arquitectura contemporánea, por su trabajo y por la influencia que proyectaron hasta nuestros días. Todos, menos uno, desarrollaron sus ideas en Europa. Se conocieron, se amistaron y enemistaron, se influyeron y se criticaron.

En la Alemania de Weimar, un joven arquitecto llamado Walter Gropius, fundó la escuela de diseño y arquitectura conocida como Bauhaus y cuya traducción es "casa estatal de la construcción” donde se enseñaba a los estudiantes a utilizar materiales modernos e innovadores para crear edificios, muebles y objetos originales. A partir de 1926, Gropius se dedicó intensamente a los grandes bloques de viviendas, en los que veía la solución a los problemas urbanísticos y sociales. En 1933 la Bauhaus es cerrada por el régimen nazi y tanto Gropius como su gran colaborador Ludwig Mies van der Rohe migran a Estados Unidos.

En los años veinte, durante la tercera república en Francia surge el trabajo del arquitecto suizo Charles Jeanneret-Gris, más conocido como Le Corbusier quién se sintió atraído desde joven por las posibilidades del hormigón armado. Para Le Corbusier la arquitectura era "el juego sabio, correcto y magnífico de los volúmenes bajo la luz”. Fue fundador del Con- greso Internacional de Arquitectura Moderna (CIAM) que influyó en la toda la arquitectura del siglo veinte. Otro de los fundadores del CIAM fue el finlandés Alvar Aalto, entusiasta de los principios funcionalistas, la estética industrial y las superficies puras. El único no europeo del grupo fue el norteamericano Frank Lloyd Wright, conocido por las características orgánicas y funcionales de sus diseños.

Para los arquitectos vanguardistas, las formas debían ser simples y sin ornamentos, abandonando la composición académica clásica. Los nuevos materiales se debían usar desprovistos de texturas falsas y sus diseños se caracterizan por plantas y secciones ortogonales, generalmente asimétricas, ausencia de decoración en las fachadas y grandes ventanales horizontales conformados por perfiles de acero. Los espacios interiores son luminosos y diáfanos.

Sus premisas eran: "la forma sigue a la función” y "lo que funciona bien es bello".

A pesar de las críticas, su influencia en el diseño de nuestro entorno es notable, incluyendo probablemente la silla en que estamos sentados y la página y la revista que estamos leyendo.

\section{Referencias bibliográficas}

1.- Historia de la Arquitectura Moderna. Leonardo Benévolo. Editorial Gustavo Gili, Barcelona, 2010.

Ernesto Payá Hospital de Carabineros, Santiago. époque y el segundo, opulento y macizo, decae con la gran crisis de 1930 .

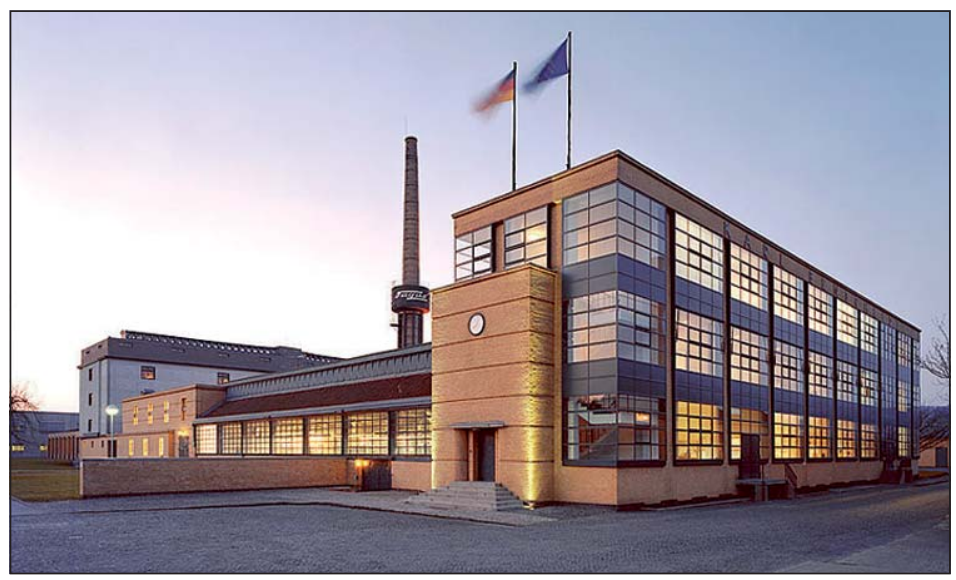

Figura 1. La fábrica Fagus en Alfeld, Alemania, construída por W. Gropius en 1911 Fotografía de Mike Reiss.

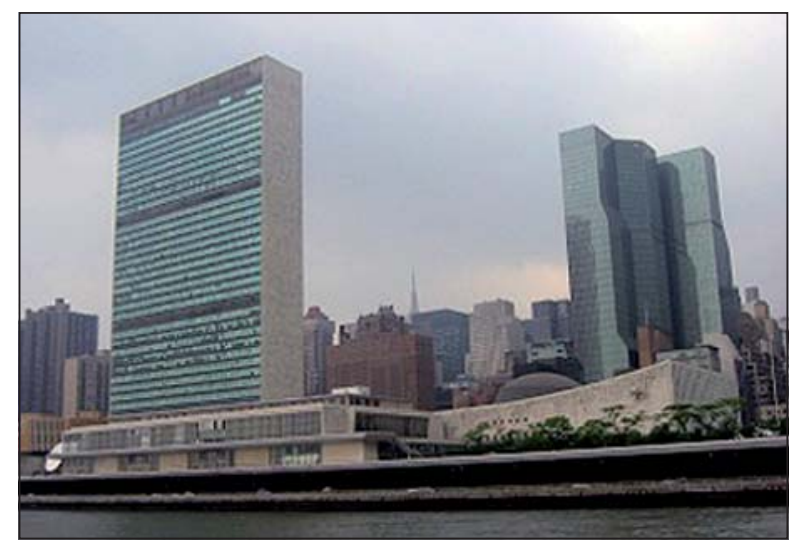

Figura 2. Sede de las Naciones Unidas en Nueva York. Construída en 1949 según un diseño original de Le Corbusier. Fotografía de Djmutex. 2005. 